\title{
Perantau Manggarai di Kelurahan Sesetan Kecamatan Denpasar Selatan
}

\author{
Fredieman Asmi ${ }^{1}$, I Ketut Kaler ${ }^{2}$, I Nyoman Suarsana ${ }^{3}$ \\ ${ }^{[123]}$ Program Studi Antropologi, Fakultas Ilmu Budaya, Universitas Udayana, Denpasar \\ ${ }^{1}$ [fredieman.asmi@gmail.com], ${ }^{2}$ [iketutkaler@gmail.com] \\ 3 [inyomansuarsana.58@gmail.com] \\ *Corresponding Author
}

\begin{abstract}
This study aims to determine the implementation of IKMB in Sesetan Village, South Denpasar District. The theoretical frameworks and concepts used to support the theory of adaptation, assimilation theory and conceptual framework related to overseas culture for Manggarai people who live in the area or temporarily in Sesetan Village, South Denpasar Subdistrict. The method and technique of this research is divided into three, namely 1) methods and techniques in the form of participant observation and interview; 2) literature study method; And 3) data analysis techniques. The results obtained from the above research on the Manggarai family inhabiting on the island of Bali as a family existence that closely maintains each component of its own culture as well as in the Overseas lands as manifestations that mutually support each other by generating multicultural cultures and languages.
\end{abstract}

Keywords: Manggarai Culture, Assimilation, Adaptation, Migration.

\section{Latar Belakang}

Perkembangan teknologi dan ilmu pengetahuan di era globalisasi telah berhasil menghantarkan kesejahteraan dan berbagai kemudahan bagi manusia dalam menjalani hidupnya. Perkembangan teknologi tentunya tidak pernah berhenti, dari masa ke masa teknologi semakin canggih dan kompleks (Danesi, 2012: 240). Perkembangan teknologi ini membawa pengaruh yang begitu besar bagi manusia. Perkembangan teknologi bisa berpengaruh positif dan terkadang bisa menimbulkan efek negatif.

Konsep merantau sama dengan migrasi, yaitu perpindahan secara fisik dari satu tempat ke tempat lain secara geografis, baik yang sifatnya permanen maupun sementara (Sairin, 2001: 79).Tujuan orang merantauadalah untuk merubah peruntungan hidupnya agar bisa lebih baik. Konotasi atau makna dari pernyataan ini cenderung memposisikan kegiatan perantauan sebagai sarana pemuas kebutuhan ekonomi semata.Zaman modern seperti sekarang ini, kegiatan perantauan tidak hanya bertujuan untuk memenuhi kebutuhan ekonomi saja, melainkan sudah merambah masuk ke hal-hal yang lebih kompleks, seperti pendidikan, kesehatan, kondisi sosial, dan lain sebagainnya.

$$
\text { Nggoro (2006: }
$$

menjelaskan bahwa dari segi topografi Manggarai merupakan daerah berbukit, pegunungan, dan sebagian dataran rendah, akan tetapi Manggarai tergolong dalam iklim kering yang memungkinkan masyarakat hanya bisa bercocok tanam pada jenis tanaman musiman, seperti, kacang-kacangan, umbi-umbian, dan jagung. Kondisi seperti inilah yang menyulitkan kondisi kehidupan orang Manggarai terlebih dari aspek ekonomi. Kurangnya lapangan pekerjaan, padatnya 
penduduk, serta minimnya sarana dan prasarana pendidikan nampaknya menjadi faktor pendorong utama bagi orang Manggarai untuk melakukan migrasi atau merantau.

Provinsi Bali menjadi salah satu daerah tujuan utama para perantau asal Manggarai karena banyak faktor yang mampu menyita perhatian orang Manggarai. Setiap tahunnya jumlah pendatang asal Manggarai yang ada di Bali mengalami peningkatan. Faktor utama yang membuat orang Manggarai lebih memilih Bali sebagai tempat rantauan daripada kota besar lainnya karena kegiatan pariwisata di Bali yang sangat menjanjikan. Selain dari segi ekonomi, Bali juga memiliki sarana dan prasarana pendidikan yang begitu memadai yang tidak terdapat di Manggarai. Orang Manggarai juga menyadari akan pentingnya pendidikan, maka mereka akan datang ke Bali dengan tujuan memperoleh pendidikan setinggi mungkin agar nantinya ilmu yang didapat bisa digunakan untuk membangun Manggarai.

Perantau Manggarai yang berada di Bali membentuk sebuah kelompok ikatan keluarga yang diberi nama Ikatan Keluarga Manggarai Bali (IKMB),kelompok ini terbentuk karena ada ikatan emosional dengan adanya rasa senasib dan sepenanggungan. Awal mula dibentuknya komunitas ini berawal dari beberapa orang yang dianggap sebagai tetua-tetua dari orang Manggarai di Bali yang tergerak hatinya untuk menghimpun dan mendata keberadaan seluruh warga masyarakat Manggarai yang ada di Bali. Para tetua ini terdiri dari 9 orang, yaitu: Herman Tasi (ketua), Darius Jehabut (wakil), Olaf Margol (sekretaris),Don Bosco P.Wahi (alm) sebagai bendahara, dan sebagai anggota Nikolaus Ngabus (alm), Yohanes Kadis, Andreas Sofi, Romanus Rahu, Andreas Kur. Selain untuk mendata imigran asal Manggarai, faktor lain dibentuknya IKMB adalah sebagai wadah penyampaian informasi bagi orang Manggarai di Bali.

Berdasarkan beberapa pemaparan masalah di atas, peneliti memfokuskan penelitian pada "Perantau Manggarai di Kelurahan Sesetan Kecamatan Denpasar Selatan". Kelurahan Sesetan dipilih sebagai lokasi penelitian karena keberadaan perantau asal Manggarai sebanyak 2.433 orang.Partisipasi aktif IKMB dalam setiap kegiatan yang bernuansa kebudayaan Bali sejauh ini sering kali terpusat di wilayah Kelurahan Sesetan.

\section{Pokok Permasalahan}

Berdasarkan atas latar belakang masalah yang dijelaskan di atas, maka permasalahan yang dituangkan dalam perumusan masalah dalam penelitian ini adalah mengapa orang Manggarai merantau ke Pulau Bali? dan bagaimana strategi adaptasi perantarau Manggarai di Kelurahan Sesetan Kecamatan Denpasar Selatan?

\section{Tujuan Penelitian}

Untuk mengetahui faktor apa yang menyebabkan orang Manggarai merantau ke Pulau Bali dan untuk mengetahui strategi adaptasi perantarau Manggarai di Kelurahan Sesetan Kecamatan Denpasar Selatan.

\section{Metode Penelitian}

Lokasi dalam penelitian ini adalah Wilayah Kelurahan Sesetan. Pemilihan Kelurahan Sesetan sebagai lokasi penelitian karena dominan Perantau Manggarai berdomisili di Kelurahan Sesetan. Sumber data yang digunakan dalam penelitian ini adalah data primer dan data sekunder. Penelitian kuantitatif lebih bersifat explanation yaitu menerangkan, menjelaskan. Karena bersifat to learn about the people atau masyarakat sebagai subjek. Informan 
menurut Koentjaraningrat (1990: 43) digolongkan menjadi tiga, yakni informan pangkal, informan kunci, dan informan biasa. Instrumen pokok yang dipakai dalam penelitian ini adalah pedoman wawancara (interview guide). Teknik pengumpulan data menggunakan observasi partisipasi, wawancara, metode studi pustaka.

Teknik analisis data diperoleh dari hasil wawancara, catatan lapangan, dan dokumentasi, dengan cara mengorganisasi data ke dalam kategori, menjabarkan ke dalam unit-unit, melakukan sintesa, menyusun ke dalam pola, memilih mana yang penting dan akan dipelajari, dan membuat kesimpulan, sehingga mudah dipahami oleh penulis maupun orang lain. Hasil analisis akan dideskripsikan secara naratif tetapi tetap memperhatikan prinsip-prinsip ilmiah seperti rasional, obyektif, sistematis, kompherensif.

\section{Hasil dan Pembahasan}

\section{Faktor Pendorong Orang Manggarai} Merantau

\section{a. Keterbatasan lapangan kerja}

Keterbatasan yang dimiliki oleh masyarakat Manggarai menjadikan migrasi sebagai pilihan utama agar dapat merubah peruntungan dalam hidup. Berbekal kemampuan seadanya dan dana yang terbatas masyarakat Manggarai mampu melakukan migrasi hingga ke kota-kota besar di Indonesia, bahkan tidak jarang banyak yang melakukan migrasi hingga ke luar negeri, seperti Singapura dan Malaysia.

\section{b. Lahan pertanian yang kurang produktif}

Kondisi geografis Manggarai yang sedemikian rupa juga turut memberi dorongan kepada masyarakat untuk melakukan migrasi. Nggoro (2013: 24), bahwa topografi Manggarai terdiri dari gunung, bukit, dan sebagian dataran (padang). Manggarai tergolong iklim kering, dimana musim hujan berkisar antara bulan Desember sampai April dan musim kering antara bulan Mei sampai November.

\section{c. Fasilitas pendidikan yang kurang memadai}

Fasilitas Pendidikan terutama pada jenjang Perguruan tinggi di Manggarai sangat terbatas. Hal ini berdampak pada minimnya jurusan yang ditawarkan pada calon mahasiswa. Keterbatasan dalam pilihan jurusan memotivasi masyarakat Manggarai untuk melanjutkan studinya di Luar Manggarai. Hal ini harus dilakukan agar nantinya generasi muda Manggarai bisa dan mampu bersaing dalam dunia kerja yang semakin hari semakin maju.

\section{d. Kemudahan Dalam Akses Sarana Transportasi}

Faktor yang mendorong orang Manggarai untuk melakukan migrasi dalam penelitian ini peneliti berusaha mengkaitkan yang telah diutarakan oleh beberapa informan di Bali sebagai daerah tujuan migrasi mereka. Sebagaimana yang sudah dibahas pada bab sebelumnya bahwasannya Bali merupakan sebuah pulau dengan tingkat kepadatan penduduk yang cukup tinggi, meskipun demikian tetap saja orang-orang dari segala penjuru di Indonesia tertarik untuk mengadu nasib di Bali.

Faktor Penarik Masyarakat
Manggarai Melakukan Migrasi
a. Daya Tarik Wisata Bali
Ibu $\quad$ Erna $\quad$ Saleman menggungkapkan seorang perantau asal Manggarai dalam wawancara tanggal 5 April 2017

"Tara do keta lawa Manggarai sot ngo lau Bali ai Bali kota de pariwisata. Jadi do keta turis ata mai ce'e Bali kudut lako-lako liburan. Otomatis do uma duat lau Bali agu do kawe pegawe lau hitu. Gaji kole ga lumayan mese 
remo kudut mose wie leso ka'eng kilo."

Artinya, faktor utama yang menjadi daya tarik para perantau Manggarai datang ke Pulau Bali adalah karena Bali merupakan daerah tujuan wisata utama di Indonesia. Secara otomatis sebagai daerah tujuan wisata tentunya Bali membutuhkan tenaga kerja dalam jumlah yang cukup banyak. Selain itu, penghasilan yang didapat apabila bekerja di Bali cukup besar dan lumayan untuk memenuhi kebutuhan keluarga.

\section{b. Sarana Pendidikan Yang Memadai dan Lebih Kompleks}

Orang Manggarai menyekolahkan anaknya di Bali sejak menempuh pendidikan tingkat SMP ataupun SMA dikarenakan banyak sekolah-sekolah di Bali yang menawarkan pendidikan dengan kualitas tinggi lengkap dengan fasilitas asrama yang bisa menunjang bagi siswa rantauan dari luar daerah, dari segi kualitas dan biaya yang relatif murah, hal lain yang menarik minat orang luar untuk menempuh pendidikan di Bali karena fasilitas pendidikan yang sudah terbilang maju sehingga semakin memudahkan siswa atau mahasiswa dalam proses pembelajaran.

\section{c. Biaya Hidup Yang Relatif Murah}

Terlepas dari kemampuan kerja yang dimiliki orang Manggarai, mereka melihat bahwa biaya untuk hidup di Bali tergolong murah, sehingga dengan gaji seadanya mereka masih bisa bertahan hidup. Orang Manggarai meyakini jika sebagai salah satu kota besar di Indonesia, kebutuhan hidup di Bali bisa diperoleh dengan harga yang relatif lebih murah jika dibandingkan dengan Jakarta, jarak tempuh dari Manggarai ke Bali masih terbilang dekat dan murah.

\section{d. Potret Bali Yang Menawarkan Banyak Kemudahan}

Ibu Sisilia Mbulak salah seorang perantau asal Manggarai dalam wawancara tanggal 2 April 2017, mengatakan

"Pada umum ami hot mai mbeot ce'e Bali tertarik ali laseng lelo lami Bali one mai tayangan tv nehot di'a keta. Jamin tu'ung mose de masyarakat, lelo kole mbaru ce'e Bali ho'o tembok keta taung. Agu iwon ga senget kat nunduk de ata sot pernah mai ce'e Bali. Ai tae dise eme mai ce'e Bali ga berarti di'a mose ngger olon."

Artinya, pada umumnya para perantau asal Manggarai yang bermigrasi ke Bali merasa tertarik karena sering menyaksikan Bali dari tayangan di televisi. Apalagi ketika melihat kehidupan masyarakat Bali yang sejahtera dengan rumah megahnya yang terbuat dari beton menambah rasa penasaran para perantau. Ditambah lagi dengan cerita dari sanak saudara yang pernah tinggal dan mengadu nasib di Bali bahwa merantau atau bermigrasi ke Bali dapat menjamin kehidupan di kemudian hari.

\section{d. Ketersediaan Sarana Hiburan}

Faktor lain yang menarik perhatian para pendatang asal Manggarai untuk datang ke Bali karena Bali menyuguhkan banyak sarana hiburan bagi masyarakat. Sebagai masyarakat rantauan, orang Manggarai di Bali sangat membutuhkan hiburan yang mungkin tidak bisa mereka dapatkan di kampung halamannya. Tidak bisa disangkal bahwa keberadaan dunia malam di Bali merupakan faktor penarik bagi orang luar untuk datang ke Bali. Terlepas dari sisi negatif yang sering diekspos dari kehidupan malam di Bali, keberadaan hiburan malam ini nampaknya bisa menghibur masyarakat pendatang, selain hiburan malam hiburan lain seperti adanya taman bermain dan lapangan untuk olahraga membuat para pendatang 
asal Manggarai serasa berada di kampung halaman sendiri.

\section{Strategi Perantau Manggarai di Kelurahan Sesetan \\ Keadaan Perantau Manggarai di Kelurahan Sesetan}

Umur jumlah pendatang usia 2130 tahun ke atas terbilang cukup banyak. Ini menandakan bahwa banyak perantau asal Manggarai yang berusia kerja di Kelurahan Sesetan. Secara keseluruhan pendatang asal Manggarai yang berdomisili di Kelurahan Sesetan pada umumnya sudah memasuki usia dewasa dan usia kerja.

Tingkat pendidikan yang menempuh pendidikan di perguruan tinggi cukup banyak yaitu sebesar 283 orang $(11,63 \%)$. Meskipun mayoritas sudah mengenyam pendidikan perguruan tinggi, tidak sedikit pula pendatang asal Manggarai yang tidak bersekolah. Tercatat sekitar 2.014 orang $(82,77 \%)$ yang tidak bersekolah, 15 orang $(0,62 \%)$ TK, SD sebanyak 100 orang $(4,11 \%)$, SMP 10 orang $(0,42 \%)$, dan SMA sebanyak 11 orang $(0,45 \%)$.

Berdasarkan umur, profesi yang paling banyak digeluti oleh para pendatang asal Manggarai yang berdomisili di Kelurahan Sesetan adalah SPG/SPB yaitu mencapai jumlah 697 orang $(28,64 \%)$. Tenaga pengajar (guru dan dosen) sebanyak 23 orang $(0,94 \%)$, pegawai swasta sebanyak 428 orang (10,12\%), TNI/POLRI sebanyak 18 orang $(0,73 \%)$, tenaga medis (dokter, bidan, dan perawat) sebanyak 12 orang $(0,49 \%)$, sopir sebanyak 89 orang $(3,65 \%)$, pedagang sebanyak 32 orang $(1,32 \%)$, pengusaha sebanyak 15 orang $(0,62 \%)$. Sisanya adalah kelompok anakanak dan remaja yang sedang bersekolah atau tidak bekerja sebanyak 1.119 orang $(45,99 \%)$.

Berdasarkan agama, mayoritas pendatang asal Manggarai di Kelurahan
Sesetan menganut agama Katolik (2.170 orang, 89,19\%),yang menganut agama islam sebanyak 33 orang $(1,35 \%)$, dan yang menganut agama Kristen sebanyak 230 orang $(9,46 \%)$.

\section{Sejarah Singkat Berdirinya Ikatan Keluarga Manggarai}

Awal mula terbentuknya IKAMA didorong oleh sulitnya masyarakat Manggarai di Bali dalam memperoleh informasi mengenai aspek sosial dan budaya Manggarai sementarakuantitas masyarakat Manggarai yang ada di Bali saat itu dapat dikatakan dalam jumlah yang cukup banyak. Berdasarkan data IKAMA, pada tahun 1982 terdapat kurang lebih 687 jiwa perantau asal Manggarai yang terdata, yang terbagi dalam kurang lebih 230 kepala keluarga (kk). Seiring dengan perkembangan yang terjadi pada masa itu, terjadi perdebatan tersendiri di dalam tubuh kepengurusan IKAMA, maka berdasarkan keputusan rapat pengurus IKAMA pada tahun 1987 dihasilkan keputusan tentang perubahan nama dari IKAMA menjadi IKMB. Keputusan ini berdasar pada pertimbangan bahwa dibentuknya IKAMA dimaksudkan sebagai wadah bagi seluruh masyarakat Manggarai yang ada di Bali, sehingga pemilihan IKMB dianggap lebih merepresentasikan kehadiran masyarakat Manggarai di Bali.

\section{Interelasi IKMB Di Kelurahan Sesetan} 1. Internal IKMB

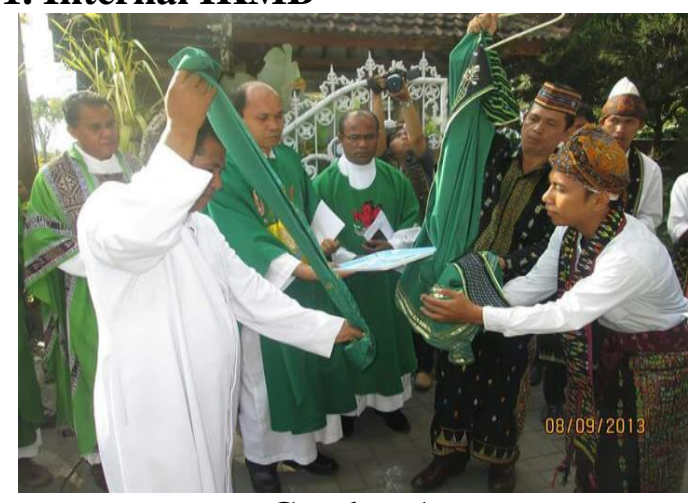

Gambar 1

Pesta Perak Rm. Yosef Wora di Seminari Tuka, Dalung 
dalam Nuansa Adat Manggarai

Dokumen: Alfred tahun 2013.

Wujud nyata lain yang dilakukan oleh IKMB dalam memanifestasikan budaya Manggarai adalah melalui pargelaran seni budaya Manggarai yang dilaksanakan di GOR Ngurah Rai, Denpasar pada Maret 2017.

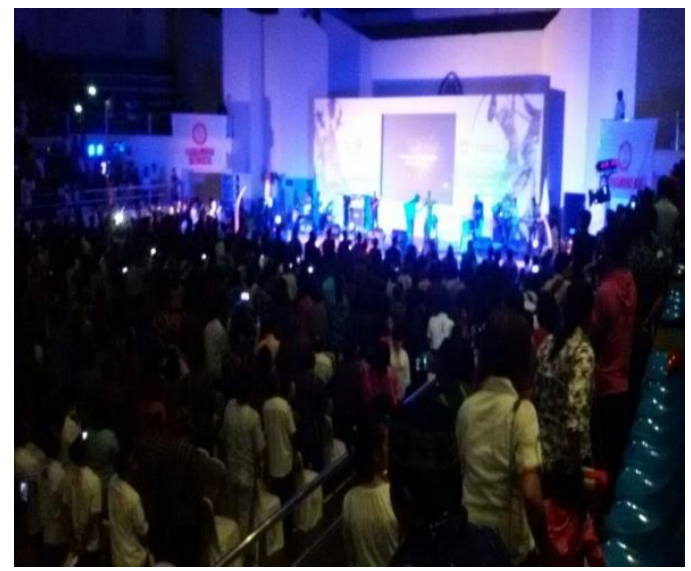

Gambar 2

Perayaan Natal dan Tahun Baru bersama Flobamora Bali tahun 2017 di GOR Ngurah Rai

Dokumen: Alfred tahun 2017

Wujud nyata dalam menunjukkan eksistensi dari IKAMA yaitu dalam membangun solidaritas bersama anggota melalui keluarga suka duka, contoh di bawah ini menggambarkan kekuatan tradisi adat Manggarai apabila ada kerabat atau kenalan yang meninggal maka akan dilakukan upacara terakhir agar rohnya menjadi tenang.

\section{Eksternal IKMB}

Eksistensi yang sering dilakukan oleh masyarakat Manggarai adalah bentuk toleransi kepada setiap adat istiadat yang ada di Bali khususnya di Kelurahan Sesetan, Denpasar Selatan. Bentuk-bentuk yang sering diterapkan dalam suatu hubungan berupa, gotongroyong di banjar, dan ngayah di pura apabila salah satu masyarakat yang sudah terikat batin menjadi masyarakat Hindu dalam suatu hubungan keluarga atau terjalinnya ikatan pernikahan, dan yang wajib dilakukan adalah mengabdikan diri di pura.

Pulau Bali yang juga dikenal sebagai "Pulau Seribu Pura" memiliki ritual khusus dalam memperlakukan leluhur atau sanak saudara yang telah meninggal. Apabila di tempat lain orang yang meninggal umumnya dikubur, tidak demikian dengan masyarakat Hindu Bali. Sebagaimana penganut Hindu di India, mereka akan menyelenggarakan upacara kremasi yang disebut Ritual Upacara Adat Ngaben, yaitu ritual pembakaran mayat sebagai simbol penyucian roh orang yang meninggal.

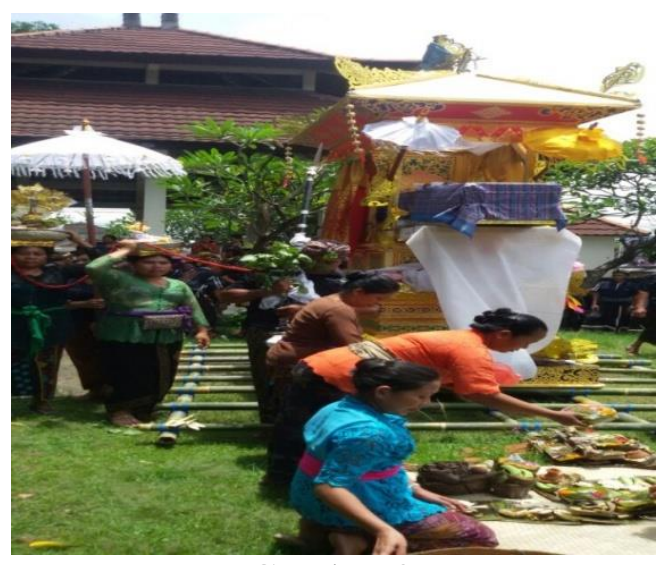

Gambar 3

Ritual upacara adat Ngaben di Kelurahan Sesetan

Dokumen: Alfred tahun 2017.

Ritual Adat Ngaben biasanya diselenggarakan secara meriah dan mengikutsertakan ratusan hingga ribuan orang yang terdiri dari sanak saudara maupun penduduk banjar setempat (organisasi sosial khas masyarakat Bali setingkat dengan Rukun Warga). Dalam perkembangannya, upacara unik ini juga menjadi salah satu agenda pariwisata, di mana wisatawan domestik dan mancanegara turut serta menyaksikan ritual ini, terutama pada tahapan upacara utama, yaitu kremasi jenazah.

IKMB ingin membuktikan bahwa para pendatang asal Manggarai datang ke Bali tidak hanya ingin memenuhi tujuannya saja, melainkan secara 
bersama-sama ingin membentuk suatu ikatan kekeluargaan dengan masyarakat di Bali. Masyarakat pendatang dari Manggarai tidak hanya ingin mencari keuntungan pribadi semata di Bali, tetapi ingin membangun relasi dan turut membangun Bali yang dianggap sebagai kampung halaman kedua.

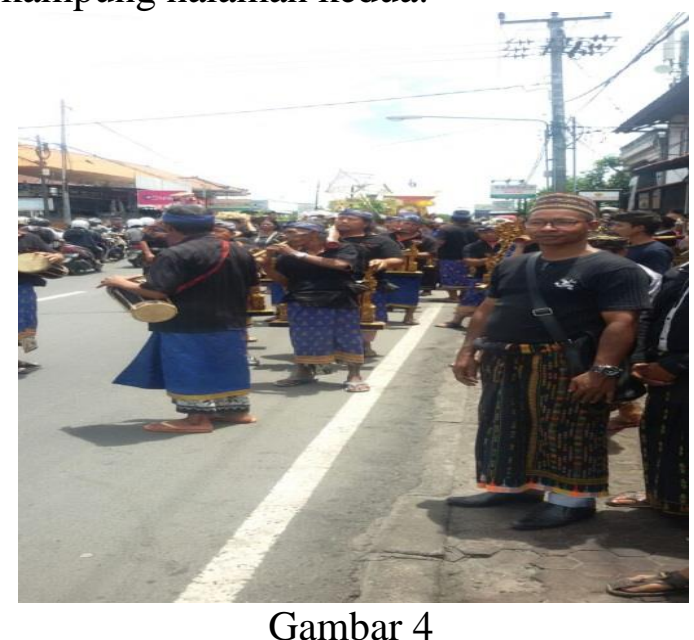

IKMB pada upacara Ngaben di Kelurahan Sesetan

Dokumen: Alfred tahun 2017.

Keterlibatan lain IKMB dalam upacara adat atau keagamaan di Sesetan terjadi pada upacara adat ngidih dalam adat perkawinan orang Bali. Tradisi adat di Bali terdapat tiga bentuk pernikahan, yakni menikah dengan cara meminang atau memadik atau ngidih dari pihak keluarga pria ke keluarga wanita, menikah dengan cara telah dijodohkan atau dikehendaki oleh pihak kedua orang tua tanpa sepengetahuan pihak gadis atau jejaka. Bentuk pernikahan berikutnya, yakni menikah dengan cara kawin lari, dimana saat ini masih terjadi di desa-desa tertentu di Bali.

Perkawinan menurut ada Bali merupakan suatu yang suci dan sakral, oleh sebab itu pada jaman weda, perkawinan ditentukan oleh seorang Resi, yang mampu melihat secara jelas, melebihi penglihatan rohani, pasangan yang akan dikawinkan. Pandangan seseorang Resi ahli atau brahmana sita, saling disatukan dapat dilihat dengan jelas. Menurut adat Hindu Bali, pernikahan dilakukan di rumah calon pengantin laki-laki pada hari yang dianggap baik oleh pendeta Hindu Bali. Biasanya pengantin baru tinggal bersama keluarga laki-laki dlam satu pekarangan rumah. Ada dua macam pernikahan, yaitu "kawin lari", dan "kawin" ngidih". Kawin lari dimana perempuan meninggalkan rumahnya untuk menikah tanpa pengetahuan orang tuanya, sudah agar jarang dilakukan. Cara pernikahan yang umum dilaksanakan dewasa ini adalah kawin ngidih, di mana pada gambar di atas mengambarkan suatu partisipasi warga Manggarai yang datang untuk meminang salah satu warga Bali yang tinggal di desa kelurahan sesetan Denpasar Selatan, menunjukkan eksistensi dalam corak pernikahan beda tradisi. Dalam kawin ngidih semua anggota banjar dari pihak laki-laki atau warga masyarakat lain tradisi harus menyaksikan upacara suci ini tetapi dari pihak perempuan tidak mengikut terlibatkan diri. Upacara ini biasanya dilanjutkan dengan pelaksanaan bukan hanya dari pihak wanita tetapi tradisi lain berkolaborasi didalam suatu pernikahan ngidih.

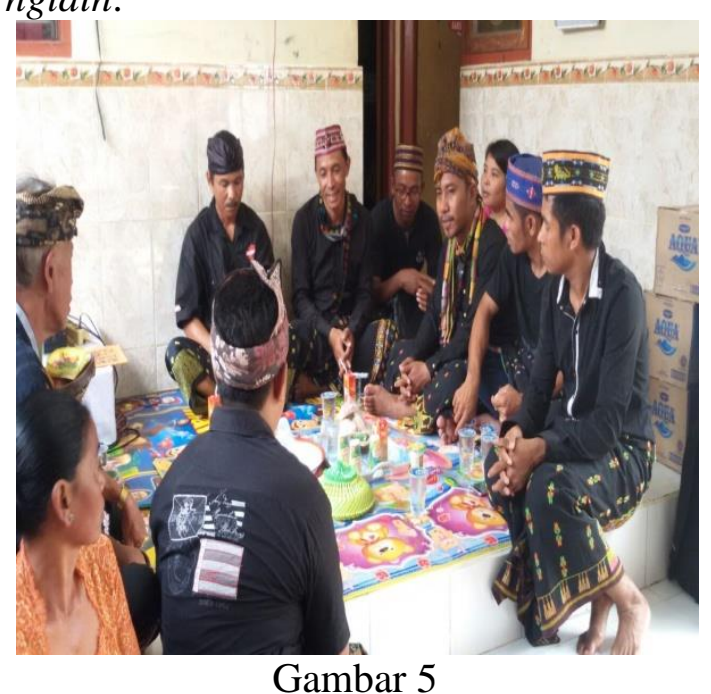

Anggota IKMB dalam upacara ngidih di salah satu rumah kerabat orang Bali Dokumen: Alfred tahun 2017. 
Nilai positif yang dapat dipetik dalam setiap keikutsertaan IKMB dalam berbagai macam upacara adat dan hajatan yang dihelat di Kelurahan Sesetan. Kondisi seperti ini sedikitnya sudah memberi gambaran bahwa disamping tujuan awal para pendatang asal Manggarai untuk merantau dan memenuhi kebutuhannya, ternyata mereka juga ingin membangun relasi dengan pihak-pihak lain yang berada pada satu lingkungan dengan mereka. Hal-hal semacam ini perlu untuk dilestarikan kedepannya untuk menjaga hubungan baik yang sudah terjalin antara masyarakat etnis Manggarai dengan masyarakat etnis Bali atau etnis lainnya.

Eksistensi IKMB di Kelurahan Sesetan tidak bisa diragukan lagi, IKMB sudah sering berpartisipasi dalam setiap kegiatan dan upacara besar di Bali secara khusus di Sesetan. Apa yang dilakukan oleh IKMB ini secara tidak langsung telah membangun kepercayaan masyarakat Bali akan etnis Manggarai sebagai warga pendatang. Selain itu, apa yang IKMB lakukan adalah bentuk pengabdian dan rasa terima kasih mereka kepada Bali yang sudah menerima mereka sebagai keluarga di tanah perantauan.

\section{SIMPULAN}

Bali merupakan salah satu tujuan rantau yang banyak dihuni oleh masyarakat manggaraidan merupakan salah satu pulau yang terdapat di bagian tengah Indonesia. Bali yang lebih dikenal dengan sebuatan pulau dewata sebagai daerah tujuan wisata merupakan daerah yang memiliki sarana dan pra sarana serta fasilitas pendidikan yang lengkap, membuka banyak lahan pekerjaan dan banyak memberikan kesempatan bagi para penduduk pendatang dalam mencari pekerjaan maupun melanjutkan pendidikan. Masyarakat Manggarai merupakan salah satu suku pendatang dari sekian banyak etnis yang mendiami pulau Bali. Berbagai alasan yang melatarbelakangi masyarakat Manggarai datang dan tinggal menetap di pulau Bali, faktor yang dominan adalah bekerja dan melanjutkan pendidikan.

Provinsi Bali atau yang lebih dikenal luas dengan sebutan Pulau Bali atau Pulau Dewata merupakan destinasi wisata terbesar untuk kawasan Indonesia, baik lokal maupun internasional. Konsekwensi dari hal tersebut adalah adanya percampuran budaya atau mix multikultural yang terjadi secara alami. Hal ini secara langsung membawa pengaruh terhadap eksistensi IKMB, yang mana IKMB secara tidak langsung dituntut untuk beradaptasi dan berasimilasi dengan situasi dan kondisi alamiah yang terjadi di pulau Bali.

Seiring berkembangnya zaman ada banyak perubahan yang terjadi dalam kehidupan manusia, termasuk perubahan budaya yang terjadi di kalangan masyarakat Bali dengan adanya kehadiran Masyarakat Manggarai yang merantau, akan tetapi dari setiap dimensi menimbulkan suatu warna baik dari segi tradisi, kultur, agama, status sosial, pekerjaan dan lain-lain. Menggambarkan bahwa eksistensi masyarakat perantau yang tinggal menetap adalah saling memberikan perubahan multikulturalnya dan tetap saling menghargai.

\section{DAFTAR PUSTAKA}

Baker, J.W.M. 1984, Filsafat Kebudayaan Sebuah Pengantar. Yogyakarta: Kanisius.

Haviland, A William. 1993, Antropologi edisi ke empat. Jakarta: Erlangga.

Ilmi, Nurul. 2014, Makala Sumber Data Penelitian Kualitatif. www.kebudayaan.com

Kaelan, 2009, Filsafat Bahasa Semiotika dan Hermeneutika. Yogyakarta: Paradigma. 
Kleden, Hargens. 2011. Gereja Menyapa Manggarai. Jakarta: Parrhesia Institute.

Koentjaraningrat. 1990, Kebudayaan Mentalitas dan Pembangunan. Jakarta: PT. Gramedia Pustaka Utama.

Koentjaraningrat. 2014, Pengantar Antropologi I. Jakarta: Rieneka Cipta.

Mazali, Amir. 2009,Antropologi dan Pembangunan Indonesia. Jakarta: Kencana.

Nggoro, Adi M. 2006,Budaya Manggarai Selayang Pandang. Ende: Nusa Indah.

Nugroho, Puspo. 2015,Metodologi

\section{Penelitian}

Antropologi.www.pusponugroho. wordpress.com.

Pilliang, Amir Y. 1999, Hipersemiotika Tafsir Cultur Studies atas Matinya Makna. Bandung: Jalasutra.

Prasedjo, Adi. Adaptasi Antropologi. Jakarta, 28 Januari.

Sairin, Sjafri. 2002,Perubahan Sosial Masyarakat Indonesia Perspektif Antropologi. Yogyakarta: Pustaka Pelajar Offset.

Soerjono, Soekanto, 1990. Sosiologi Suatu Pengantar. Jakarta: PT. Raja Grafindo Persada.

Suwardi, Endraswara, 2006. Metodologi Penelitian Kebudayaan. Yogyakarta: Gadja Mada University Press.

Toda, N Dami. 1999,Manggarai Mencari Pencerahan Historiografi. Bogor: Nusa Indah.

Verheijen. 1991,Manggarai dan Wujud Tertinggi. Jakarta: LIPI-RUL.

Zaibaski, Sofyan, 2012. Analisis dan Pengolahan Data Penelitian Kualitatif. www.sofyanzaibaski.wordpress.c om. 